\title{
Pattern and determinants of alcohol and tobacco co-use and its relationship with smoking cessation in Hong Kong
}

\author{
Raymond K. S. Ho', Patrick W. Y. Fok', Helen C. H. Chan'
}

\begin{abstract}
INTRODUCTION Alcohol and tobacco are often used together. Studies have shown that some biological factors contribute to the concurrent use of alcohol and nicotine. There have been comparatively few studies that document the concurrent prevalence and correlates of alcohol and tobacco use among adults. A better understanding of the smokers who also drink is needed to help them to quit smoking.

METHODS A retrospective case review study on smokers who voluntarily joined our service in 2014-2017 was conducted. Characteristics of tobacco users only, and alcohol and tobacco co-users were reviewed. The quit rate of smoking related to alcohol use was analyzed. Participants were contacted by phone at week 26 and 52 to ascertain smoking status and abstinence.

RESULTS There were 4602 alcohol and tobacco co-users and 2732 tobacco only users. Co-users had higher education level and better income than tobacco only users. In all, $52.24 \%$ of co-users were aged $21-40$ years. For the alcohol users, their mean AUDIT score was only 6.17 (SD: 5.67). Multivariate analysis showed that age and gender were associated with co-use while high personal income had lower odds of co-use. Quit rate decreased as the AUDIT score increased. Those who had binge drinking more than once a month had lower quit rate compared with binge drinking less than once a month at week 26 (34.2\% vs $43.19 \%, \mathrm{p}<0.0001)$.

CONCLUSIONS Alcohol and tobacco co-users should acknowledge alcohol-tobacco interactions to reduce alcohol use and prevent smoking relapse. Healthcare providers should screen for alcohol use in smoking cessation interventions.
\end{abstract}

\section{AFFILIATION \\ 1 Tung Wah Group of Hospitals Integrated Centre on Smoking Cessation, Hong Kong \\ CORRESPONDENCE TO Raymond K. S. Ho. Tung Wah Group of Hospitals Integrated Centre on Smoking Cessation, 10/F Tung Chiu Commercial Centre, 193-197 Lockhart Road, Wanchai, Hong Kong. E-mail: rayhoks@yahoo. com.hk}

\section{KEYWORDS}

smoking cessation, binge drinking, quit rate, AUDIT score, alcohol and tobacco co-use

Received: 14 October 2020 Revised: 23 December 2020

Accepted: 8 January 2020

\section{INTRODUCTION}

Alcohol and tobacco are both addictive and they are among the leading causes of preventable death in the United States ${ }^{1}$. They are often consumed together for various reasons. NESARC data have already indicated the widespread use of tobacco with alcohol' ${ }^{2}$. It has been found that smokers are more likely to drink than non-smokers and people who drink are three times more likely to smoke ${ }^{2}$. Since both substances are readily available and often used in social gatherings, this may contribute to their co-use and abuse.

Both tobacco and alcohol are carcinogenic. It is well known that cigarette smoke contains more than sixty identified carcinogens. On the other hand, the metabolite of alcohol, acetaldehyde, is also a human carcinogen as denoted by the International Agency for Research on Cancer (IARC) ${ }^{3}$. Hence, the concurrent use of alcohol and tobacco is particularly worrying because it can increase the risk of various forms of cancer such as throat, pancreatic and esophageal cancers apart from cardiovascular diseases, more than when used alone ${ }^{4,5}$.

Studies have shown that there is cross-tolerance between alcohol and tobacco. The stimulating effect 
of nicotine is counteracted by the sedating effect of alcohol and this may cause smokers to drink more alcohol $^{6}$. Alcohol's sedating effects may attenuate the physiological effects of nicotine, enhancing increase in tobacco consumption. In addition, both alcohol and nicotine in tobacco act on the mesolimbic dopamine system of the brain and stress hormone systems, which results in the reinforcing, addicting and sensitizing effects upon repeated exposure to these substances ${ }^{7}$.

According to the Thematic Household Survey 2015 Report No.59 in Hong Kong, the prevalence of daily cigarette smokers among persons aged $\geq 15$ years was $10.5 \%{ }^{8}$. The Behavioural Risk Factor Survey April 2016 in Hong Kong reported that among people aged $18-64$ years, $17.2 \%$ were regular drinkers who drank at least once a week. The males used alcohol more than females, with $25.0 \%$ of males drinking at least once a week compared to only $10.4 \%$ by females. The survey also revealed that $7.0 \%$ of people had binge drinking (consumed five or more glasses or cans of alcoholic drinks on each occasion) at least once a month, of which people aged 25-34 years had a higher rate of binge drinking ${ }^{9}$.

In order to help these alcohol users to quit smoking, a better understanding of the smokers who also drink is needed. There have been only a few studies on the concurrent prevalence and correlates of alcohol and tobacco use among adult populations from Asian countries ${ }^{10-12}$. Apparently, there is no recent survey on the co-use of alcohol and tobacco in Hong Kong. This study aims to examine the pattern on the co-use of alcohol and tobacco in relation to smoking cessation in Hong Kong.

\section{METHODS}

\section{Study design and study sample}

This study was a retrospective case review study on adult daily smokers who volunteered to receive quit smoking service in our Integrated Centre on Smoking Cessation (ICSC) from 1 January 2014 to 30 June 2017. The exclusion criteria were those aged $\leq 18$ years, mentally unstable or cognitively impaired. The participants were recruited through a smoking cessation hotline, Facebook, referral from medical practitioners or self-referral. The ICSC was funded by the Department of Health, Hong Kong SAR government and it provided free pharmacotherapy and counseling service to smokers who were Hong Kong citizens. Integrated model of counselling and pharmacotherapy in smoking cessation intervention was adopted, as suggested in the practice guidelines for treating tobacco use and dependence ${ }^{13}$.

Experienced social workers who were trained in tobacco cessation were deployed to conduct counselling with motivational interviewing technique and cognitive behavioral therapy ${ }^{14}$. The medications provided included nicotine replacement therapy (NRT) and non-NRT. The NRT used included nicotine patch, gum and lozenges, and nonNRT included bupropion and varenicline. Intensive counselling sessions each lasting about half an hour were given once a week for two weeks and then once every two weeks until the end of treatment phase, which lasted from eight to twelve weeks. Smokerlyser by Bedfont Scientific Ltd was used to measure carbon monoxide level to document tobacco abstinence at each visit.

A structured questionnaire that had been tested and adopted by local researchers ${ }^{15,16}$ was given to patients with written consent at the first visit to collect the following baseline information: sociodemographic characteristics, past health, smoking conditions, Fagerström Test on Nicotine Dependence (FTND) score, and AUDIT score (The alcohol use disorders identification test on alcohol drinking) ${ }^{17}$.

\section{Measurements}

The Fagerström Test on Nicotine Dependence (FTND) is a validated questionnaire to assess nicotine dependence of a smoker on a scale $0-10$. Scores $\geq 6$ indicate nicotine dependence and 10 corresponds to the greatest dependence.

The Alcohol Use Disorders Identification Test (AUDIT) is a questionnaire to measure drinking status with 10 items rated on a $0-4$ scale. The score of AUDIT ranges from $0-40$ where 0 indicates the subject has never drunk in the past year. A score 1-7 suggests low alcohol consumption, a score 8-14 indicates hazardous or harmful alcohol consumption, and a score of $\geq 15$ suggests the possibility of alcohol dependence or moderate-severe alcohol use disorder. The third question of AUDIT was used to detect any binge drinking problem. 


\section{Outcome measure}

Participants were contacted by phone at week 26 and 52 to ascertain smoking status and abstinence. Data of all eligible participants from 1 January 2014 to 30 June 2017 were reviewed and analyzed. The outcome measure was self-reported 7-day point prevalence abstinence rate at week 26 and 52 . Those who were lost to follow-up were treated as non-quitters based on an intention-to-treat analysis.

\section{Statistical analysis}

Statistical analyses were performed using STATA version 15 (StataCorp, 2017). The cut-off value for significance was set at $p<0.05$. Descriptive statistics were calculated for the sociodemographic variables (age, gender, marital status, education level, income), nicotine dependence (FTND), cigarettes/day, smoking self-efficacy, history of mental illness, feeling depressed in the past 2 weeks, number of previous quit attempts, current substance use, and hazardous alcohol drinking status (AUDIT). Categorical variables are presented as percentages, and the chi-squared test was used to detect significant differences between tobacco users only and alcohol and tobacco co-users. Due to the large sample size, the Shapiro-Francia W' test was performed to check for normality. Normally distributed continuous variables are presented as mean with standard deviation (SD). For continuous variables that were normally or not normally distributed, the t-test was used to compare means between tobacco users only and concurrent users of alcohol and tobacco. Previous research has found that t-tests can and should be used for heavily skewed data for studies with a large sample size. Chi-squared test was also used to detect significant differences between AUDIT score and quit rate at week 26 and week 52, as well as the significant differences between binge drinking and smoking quit rate at week 26 and week 52.

\section{RESULTS}

There were 4602 alcohol and tobacco co-users and 2732 tobacco only users (Table 1). Mean age for the former was 40.52 years and for the latter 45.2 years. Continuous variables, including cigarettes/ day, Fagerström score, number of quit attempts and scores of the importance, difficulty and confidence in quitting smoking were checked for normality. The $\mathrm{p}$ values for the Shapiro-Francia $\mathrm{W}^{\prime}$ test were all $<0.001$, indicating that these variables were not normally distributed (Supplementary file Table 1). T-test and chi-squared test results showed that no statistical

Table 1. Characteristics of the study population in Capital Region of Denmark in 2010, 2013 and 2017. Only persons with information on smoking and stress are included

\begin{tabular}{|c|c|c|c|c|}
\hline Characteristics & $\begin{array}{l}\text { Tobacco only use } \\
\qquad(\mathbf{N}=2732)\end{array}$ & $\begin{array}{c}\text { Alcohol and tobacco } \\
\text { co-use } \\
(\mathrm{N}=4602)\end{array}$ & $t$ or $\chi^{2}$ & $p$ \\
\hline Age (years), Mean (SD) & $45.20(13.16)$ & 40.52 (11.99) & & \\
\hline Age (years), n (\%) & & & $X^{2}=196.02$ & $<0.00001^{\mathrm{b}}$ \\
\hline $13-20$ & $35(1.28)$ & $122(2.65)$ & & \\
\hline $21-40$ & 1073 (39.30) & $2384(51.80)$ & & \\
\hline $41-60$ & $1215(44.47)$ & $1759(28.22)$ & & \\
\hline$>60$ & $391(14.30)$ & $304(6.61)$ & & \\
\hline missing & $18(0.65)$ & $33(0.72)$ & & \\
\hline Gender, n (\%) & & & $X^{2}=42.53$ & $<0.00001^{\mathrm{b}}$ \\
\hline Male & 1984 (72.62) & $3648(79.27)$ & & \\
\hline Female & 748 (27.38) & $954(20.73)$ & & \\
\hline Marital status, $n(\%)$ & & & $X^{2}=45.19$ & $<0.00001^{b}$ \\
\hline Married/cohabiting & 1627 (59.60) & $2649(57.60)$ & & \\
\hline Single & $714(26.10)$ & $1505(32.70)$ & & \\
\hline Separated/widowed/divorced & $334(12.20)$ & $406(8.80)$ & & \\
\hline Missing & $57(2.09)$ & $42(0.91)$ & & \\
\hline
\end{tabular}


Table 1. Continued

\begin{tabular}{|c|c|c|c|c|}
\hline Characteristics & $\begin{array}{l}\text { Tobacco only use } \\
\qquad(\mathbf{N}=2732)\end{array}$ & $\begin{array}{c}\text { Alcohol and tobacco } \\
\text { co-use } \\
(\mathrm{N}=4602)\end{array}$ & $\operatorname{tor} \chi^{2}$ & $p$ \\
\hline Education level*, n (\%) & & & $X^{2}=68.44$ & $<0.00001^{\text {b }}$ \\
\hline Illiterate & $9(0.33)$ & $9(0.20)$ & & \\
\hline Primary & 257 (9.37) & $258(5.61)$ & & \\
\hline Secondary & $1560(57.10)$ & $2862(62.19)$ & & \\
\hline Post-Secondary & $283(10.36)$ & $582(12.64)$ & & \\
\hline University & $231(8.46)$ & $578(12.56)$ & & \\
\hline Missing & $392(14.35)$ & $313(6.80)$ & & \\
\hline Monthly income ${ }^{* *}(\mathrm{HK}), \mathrm{n}(\%)$ & $N=2159$ & $\mathrm{~N}=3765$ & $X^{2}=103.17$ & $<0.0001^{\mathrm{b}}$ \\
\hline$<10000$ & $481(22.28)$ & $563(14.95)$ & & \\
\hline 10000-19999 & 902 (41.78) & $1762(46.80)$ & & \\
\hline 20000-29999 & $344(15.93)$ & $870(23.10)$ & & \\
\hline$\geq 30000$ & $432(20.01)$ & $570(15.15)$ & & \\
\hline Missing & $573(20.97)$ & $837(18.19)$ & & \\
\hline Cigarettes/day, Mean (SD) & $18.62(9.13)$ & $18.14(8.75)$ & $t=2.19$ & $p=0.0282^{b}$ \\
\hline Fagerström score, Mean (SD) & $5.32(2.37)$ & $5.23(2.42)$ & $t=1.67$ & $p=0.0956$ \\
\hline Confidence score, Mean (SD) & $63.62(25.56)$ & 60.79 (22.79) & $t=4.86$ & $p<0.0001^{b}$ \\
\hline Importance score, Mean (SD) & $81.58(18.32)$ & $80(18.62)$ & $\mathrm{t}=3.49$ & $p=0.0005^{b}$ \\
\hline Difficulty score, Mean (SD) & $73.23(23.58)$ & $74.82(25.26)$ & $t=-2.654$ & $p=0.008^{b}$ \\
\hline History of mental illness ${ }^{* *}, \mathrm{n}(\%)$ & $485(17.75)$ & $487(10.58)$ & $x^{2}=79.00$ & $\mathrm{p}<0.0001^{\mathrm{b}}$ \\
\hline Feeling depressed in the past 2 weeks, n (\%) & 639 (23.38) & $1084(23.55)$ & $X^{2}=0.07$ & $p=0.936$ \\
\hline Number of previous quit attempts, Mean (SD) & $1.46(2.84)$ & $1.52(2.80)$ & $t=0.8565$ & $p=0.3918$ \\
\hline Current substance use, n (\%) & $7(0.26)$ & $16(0.35)$ & $X^{2}=0.46$ & $p=0.498$ \\
\hline AUDIT score ${ }^{\mathrm{a}}, \mathrm{n}(\%)$ & $N=2732$ & $\mathrm{~N}=4602$ & NA & \\
\hline 0 & $2732(100)$ & NA & & \\
\hline $1-8$ & NA & $3427(74.50)$ & & \\
\hline $9-15$ & NA & $800(17.40)$ & & \\
\hline $16-19$ & NA & $200(4.34)$ & & \\
\hline$\geq 20$ & NA & $173(3.76)$ & & \\
\hline Mean (SD) & NA & $6.17(5.67)$ & & \\
\hline
\end{tabular}

*Missing data on education: 313 for drinker and 392 for non-drinker. ${ }^{* *}$ Missing data on income: 573 for non-drinker and 837 for drinker. ${ }^{* *}$ Missing data on mental illness: 33 for drinker and 37 for non-drinker. a Missing data on AUDIT score: 2. b p $<0.05$ is statistically significant. HK: 1000 Hong Kong dollars about 130 US\$. NA: not applicable.

difference was found in cigarettes/day, Fagerström score, number of previous quit attempts, and current substance use between these two groups. On the other hand, co-users had higher education level and better income than tobacco only users. There were significantly more unmarried subjects and more male in the co-users, of whom $52.24 \%$ were aged $21-40$ years. For these alcohol users, their mean AUDIT score was only 6.17 (SD: 5.67).

Univariate analysis of co-users of alcohol and tobacco revealed that age, female gender, married, divorced, separated and widowed, lower education level and lower personal income were associated with higher odds of co-use of these substances, whereas Fagerström score, cigarettes/day and previous quit attempts were not associated with couse (Table 2). Multivariate analysis showed that age and gender were associated with co-use while a high monthly personal income $\geq 30000$ HK (1000 Hong Kong dollars about 130 US\$) had lower odds of co- 
use (Table 3 ).

In Table 4, the abstinence rate at week 26 for drinkers was $40.96 \%$ (95\% CI: $0.395-0.424)$ versus 40.92 (95\% CI: 0.391-0.428) for non-drinkers, and at week 52 it was $36.09 \%$ (95\% CI: $0.347-0.375$ )

Table 2. Adjusted odds ratios (AOR) and 95\% CI for current co-users of tobacco and alcohol as determined by univariate analysis, Hong Kong 2014-2017

\begin{tabular}{|c|c|c|c|}
\hline Variables & AOR & $95 \%$ CI & $p$ \\
\hline Age (years) & 1.030 & $1.026-1.034$ & $<0.0001^{\mathrm{a}}$ \\
\hline \multicolumn{4}{|l|}{ Gender } \\
\hline Male (Ref.) & 1 & & \\
\hline Female & 1.442 & $1.291-1.610$ & \\
\hline \multicolumn{4}{|l|}{ Marital status } \\
\hline Single (Ref.) & 1 & & $<0.0001^{\mathrm{a}}$ \\
\hline Married/cohabiting & 1.295 & $1.162-1.443$ & $<0.0001^{\mathrm{a}}$ \\
\hline Divorced/widowed/separated & 1.734 & $1.463-2.055$ & \\
\hline \multicolumn{4}{|l|}{ Education } \\
\hline Primary or below (Ref.) & 1 & & $<0.0001^{\mathrm{a}}$ \\
\hline Secondary & 0.547 & $0.457-0.655$ & $<0.0001^{\mathrm{a}}$ \\
\hline Post-Secondary & 0.488 & $0.391-0.609$ & $<0.0001^{\mathrm{a}}$ \\
\hline University & 0.401 & $0.319-0.504$ & \\
\hline \multicolumn{4}{|l|}{ Monthly income (1000×HK) } \\
\hline$<10$ (Ref.) & 1 & & 0.658 \\
\hline 10-19.9 & 1.060 & $0.819-1.371$ & $0.002^{\mathrm{a}}$ \\
\hline $20-29.9$ & 0.685 & $0.540-0.870$ & $<0.0001^{\mathrm{a}}$ \\
\hline$\geq 30$ & 0.505 & $0.405-0.631$ & 0.096 \\
\hline Fagerström score & 1.017 & $0.997-1.037$ & $0.028^{\mathrm{a}}$ \\
\hline Mean cigarettes/day & 1.006 & $1.001-1.011$ & \\
\hline \multicolumn{4}{|l|}{ Previous quit attempts } \\
\hline No (Ref.) & 1 & & 0.903 \\
\hline Yes & 1.007 & $0.901-1.126$ & \\
\hline
\end{tabular}

a $p<0.05$ statistically significant. HK: 1000 Hong Kong dollars about 130 US\$. vs $37.19 \%$ (95\% CI: 0.354-0.390), respectively. However, for heavy drinkers with AUDIT score $>15$, the abstinence rate dropped to $26.67 \%$ (95\% CI: $0.224-0.314$ ) at week 26 and $21.6 \%$ (95\% CI: 0.177 0.261 ) at week 52. As shown in Figure 1, there is a decreasing trend in the quit rate as the AUDIT score increases. Table 5 also shows that the quit rate of those who never binge drank, or binge drank less than once a month, was significantly higher than

Table 3. Adjusted odds ratios (AOR) and 95\% CI for current co-users of tobacco and alcohol as determined by multiple logistic regression analysis, Hong Kong 2014-2017

\begin{tabular}{lccc} 
Variables & AOR & $95 \%$ CI & $p$ \\
\hline Age (years) & 1.025 & $1.018-1.031$ & $<0.0001^{\mathrm{a}}$ \\
Gender & 1.388 & $1.187-1.623$ & $<0.0001^{\mathrm{a}}$ \\
Marital status & & & \\
Single (Ref.) & 1 & & \\
Married/cohabiting & 1.024 & $0.884-1.185$ & 0.755 \\
Divorced/widowed/separated & 1.011 & $0.801-1.275$ & 0.927 \\
Education & & & \\
Primary or below (Ref.) & 1 & & \\
Secondary & 1.051 & $0.807-1.370$ & 0.710 \\
Post-Secondary & 1.073 & $0.785-1.466$ & 0.658 \\
University & 0.977 & $0.710-1.344$ & 0.885 \\
Monthly income (1000×HK) & & & \\
<10 (Ref.) & 1 & & \\
10-19.9 & 1.026 & $0.773-1.362$ & 0.858 \\
20-29.9 & 0.747 & $0.573-0.973$ & $0.030^{\mathrm{a}}$ \\
$\geq 30$ & 0.568 & $0.442-0.729$ & $<0.0001^{\mathrm{a}}$ \\
Fagerström score & 1.000 & $0.967-1.034$ & 0.989 \\
Mean cigarettes/day & 1.005 & $0.996-1.015$ & 0.244 \\
Previous quit attempts & 1.035 & $0.900-1.190$ & 0.631 \\
\hline & & & \\
\hline
\end{tabular}

a $p<0.05$ statistically significant. HK: 1000 Hong Kong dollars about 130 US\$.

Table 4. Relationship between AUDIT score and quit rate at 26 and 52 weeks

\begin{tabular}{|c|c|c|c|c|}
\hline AUDIT score & $\begin{array}{c}\text { Quit rate at week } 26 \\
n(\%)\end{array}$ & $95 \%$ CI & $\begin{array}{c}\text { Quit rate at } \\
\text { week } 52 \\
n(\%)\end{array}$ & $95 \%$ CI \\
\hline $1-35$ & $1884(40.96)$ & $0.395-0.424$ & 1660 (36.09) & $0.347-0.375$ \\
\hline $1-8$ & $1488(43.42)$ & $0.418-0.451$ & 1325 (38.69) & $0.370-0.403$ \\
\hline $9-15$ & 297 (37.13) & $0.338-0.405$ & 255 (31.88) & $0.287-0.352$ \\
\hline$>15$ & $100(26.67)$ & $0.224-0.314$ & 81 (21.60) & $0.177-0.261$ \\
\hline 0 & 1118 (40.92) & $0.391-0.428$ & 1016 (37.19) & $0.354-0.390$ \\
\hline
\end{tabular}

Those who were lost to follow-up were treated as non-quitters based on an intention-to-treat analysis. 
Figure 1. Relationship of AUDIT score and quit rate

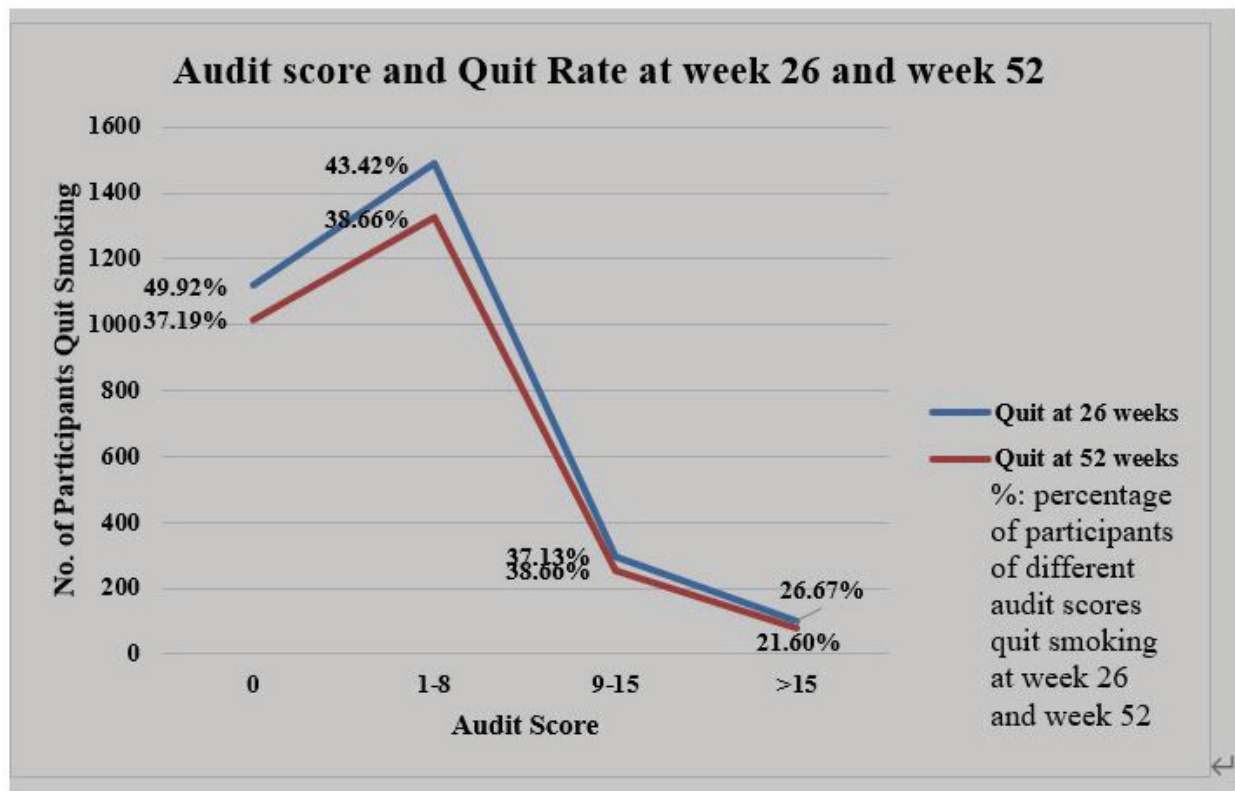

Table 5. Relationship between binge drinking and quit rates at 26 and 52 weeks

\begin{tabular}{|c|c|c|c|c|c|c|}
\hline Binge drinking vs quit rate & $\begin{array}{l}\text { Binge drinking never or } \\
\text { less than once a month } \\
\qquad \begin{array}{c}(\mathrm{N}=3605) \\
n(\%)\end{array}\end{array}$ & $\begin{array}{l}\text { Binge drinking at least } \\
\text { once a month } \\
\left(\begin{array}{c}\mathrm{N}=1073) \\
n(\%)\end{array}\right.\end{array}$ & $x^{2}$ & $\begin{array}{l}\text { Logistic } \\
\text { regression } \\
\text { coefficient }\end{array}$ & $95 \%$ CI & $p$ \\
\hline Quit rate at 26 weeks & & & 19.18 & 0.34 & $0.189-0.497$ & $\mathrm{p}<0.0001^{\mathrm{a}}$ \\
\hline Quit & $1557(43.19)$ & $367(34.20)$ & & & & \\
\hline Did not quit & 1433 (39.75) & $476(44.36)$ & & & & \\
\hline Missing & $615(17.06)$ & $230(21.44)$ & & & & \\
\hline Quit rate 52 weeks & & & 38.22 & 0.50 & $0.036-0.383$ & $\mathrm{p}<0.0001^{\mathrm{a}}$ \\
\hline Quit & 1406 (39.00) & 295 (27.49) & & & & \\
\hline Did not quit & $1486(41.22)$ & $516(48.09)$ & & & & \\
\hline Missing & 713 (19.78) & $262(24.42)$ & & & & \\
\hline
\end{tabular}

a $p<0.05$ statistically significant. Those who were lost to follow-up were treated as non-quitters based on an intention-to-treat analysis.

those who engaged in binge drinking more than once a month, at week 26 and week 52 .

\section{DISCUSSION}

Prevalence of alcohol and tobacco use in other countries and in Hong Kong

Tobacco and alcohol use are personal life-style choices and yet have an important public health impact. The US National Epidemiologic Survey on Alcohol and Related Conditions (NESARC) in 2001 indicated the widespread co-use of alcohol and tobacco in the USA: $21.7 \%$ of adults used both alcohol and tobacco, representing approximately 46.2 million people. Younger people tended to have a higher prevalence of alcohol use disorders, nicotine dependence and couse $^{18}$. Tobacco and alcohol co-use varied with age, gender and ethnicity, and men had higher rates of co-use than women ${ }^{19}$.

There are only a few studies on tobacco and alcohol co-use in Asian countries. In Thailand, the prevalence of current smoking with harmful and hazardous alcohol consumption was $10.2 \%{ }^{20}$. In Cambodia, the Tobacco Control Leadership Training Survey of 2005-2006 revealed that $40-55 \%$ of male 
smokers used alcohol in the past week ${ }^{12}$. In India, the prevalence of co-use of tobacco and alcohol among men aged 18-59 years was $23.5 \%$. In Hong Kong we did not have any data on prevalence of concurrent use of alcohol and tobacco in adults ${ }^{10}$.

Alcohol consumption per capita varies significantly between countries with different economic status, culture and religion. Globally, it was estimated that $6.42 \mathrm{~L}$ pure alcohol per capita were consumed by the adult population (aged $\geq 15$ years) in $2015^{21}$. According to the WHO Global status report on non-communicable diseases 2011 in Asia, the Republic of Korea consumed 14.81 L per capita, China consumed 5.56 L per capita, and Singapore $1.54 \mathrm{~L}$ per capita ${ }^{22}$, while the alcohol consumption per capita in Hong Kong was estimated to be $2.64 \mathrm{~L}$ in 2010 .

In Hong Kong, the behavioral risk factor survey conducted by the Department of Health HKSAR in 2016 indicated that $70.5 \%$ of the respondents reported that they had a drink containing alcohol during the past year. On the other hand, $29.5 \%$ of the respondents reported that they had never drunk alcohol during the past year prior to the survey; $4.0 \%$ reported drinking daily and about $40.0 \%$ reported drinking less than once a month ${ }^{23}$.

In contrast to population surveys in other countries, the current study was on smokers in a smoking cessation service, and it revealed that $37.3 \%$ of all smokers never use alcohol whereas $62.7 \%$ of the smokers were current users of alcohol in the past year, with various quantities and frequencies. In two population surveys in Canada, the Canadian Community Health Survey (CCHS) and the Canadian Alcohol and Drug Monitoring Survey (CADUMS), $24 \%$ of current smokers scored $>8$ on the AUDIT scale $^{23}$. Our study yielded a similar finding on smokers, with $25.5 \%$ scoring $>8$ on AUDIT scale.

\section{Alcohol and quitting smoking}

Greater alcohol consumption is associated with decreased odds of smoking cessation ${ }^{24,25}$. In our study, the quit rate between tobacco and concurrent alcohol and tobacco users did not differ appreciably. This might be due to the fact that most of our smokers were mild to moderate drinkers as $74.5 \%$ had AUDIT scores $<9$. However, as seen in Figure 1, there is a decreasing trend of quitting as the AUDIT score increases. When we dichotomize alcohol users with AUDIT score $>15$, there is a significant decrease in quit rate in this group and this concurs with overseas findings.

\section{Illicit drug use and smoking}

The US National Survey on Drug Use and Health among persons $\geq 12$ years (NSDUH) 2002-2014 revealed that approximately $20.81 \%$ of cigarette smokers also used an illicit drug in the past month ${ }^{26}$. In Hong Kong, the prevalence of illicit drug use alone is much lower than in Western countries. The prevalence of 6-month substance use for males aged 18-60 years was estimated to be $4.4 \%^{27}$. There is apparently no local population studies on the concurrent use of tobacco and illicit drugs. The current cohort study, which is not a population survey, only revealed 0.26 $\%$ smokers had past-year substance use while only $0.35 \%$ tobacco and alcohol co-users had past-year substance use.

\section{Correlates of co-use of alcohol and tobacco}

Several studies have investigated the relationship between socioeconomic factors and the prevalence of smoking or alcohol drinking separately, but few studies have investigated the relationship between socioeconomic factors and concurrent tobacco and alcohol consumption ${ }^{28,29}$.

In a Thailand study, alcohol and tobacco cousers were mostly illiterate, manual workers ${ }^{30}$. In an Indian study, an inverted $\mathrm{U}$ or $\mathrm{V}$-shape relation on age was found in tobacco and alcohol co-users ${ }^{10}$. The prevalence was lowest for age groups 18-24 and 50-59 years. Their main risk factors for high rate of co-use were low education level and working in the informal sector. There are some similarities with our study where co-users are less educated with lower personal income, and higher prevalence in the age group 21-40 years. One interesting finding is that our female smokers are more likely to be co-users of alcohol. This might be due to the fact that our female population is more affluent, and socially and financially independent. However, this needs to be confirmed by further studies.

\section{Limitations}

There are some limitations in this study. First, analyses are based on retrospective case review design and therefore the sampling frame is restricted to users 
of our service. Data on tobacco and alcohol use are entirely based on participants' self-report. People who are co-using may be using cigarettes and alcohol at the same time while in social gatherings or they might just be using both substances at separate times. We have no data on how they use both substances in these two different situations. The intensity and frequency of alcohol use is assessed by the AUDIT score and the quantity of alcohol consumption is not evaluated. The quit rate was self-reported and not biochemically validated.

\section{CONCLUSIONS}

This study highlights the importance of noting the co-occurrence of alcohol and tobacco. The current study and other studies have documented that tobacco and nicotine can increase alcohol use and smoking relapse. We should acknowledge the effect of alcoholtobacco interaction and try to reduce alcohol use and prevent smoking relapse in a more proactive manner in smoking cessation interventions. To improve the health condition of the smoking population, policies and strategies must be formed to reduce the co-use of tobacco and alcohol, especially targeted at those with lower education level and economic status. Increasing health education and awareness about the harmful effects of tobacco and alcohol use can reduce co-occurrence of tobacco and alcohol. Sherry et al. ${ }^{31}$ have remarked that in general, there has been a lack of attention to alcohol consumption in the smoking cessation literature. It is worth screening people on alcohol use during smoking cessation interventions so that appropriate advice on alcohol use can be given.

\section{REFERENCES}

1. Mokdad AH, Marks JS, Stroup DF, Gerberding JL. Actual causes of death in the United States, 2000. JAMA. 2004;291(3):1238-1245. doi:10.1001/jama.291.10.1238

2. Falk DE, Yi H, Hiller-Sturmhöfel S. An epidemiologic analysis of co-occurring alcohol and tobacco use disorders: Findings from the National Epidemiologic Survey on Alcohol and Related Conditions. Alcohol Res Health. 2007;29(3):162-171. PMID:17373404.

3. International Agency for Research on Cancer, World Health Organization. Alcohol consumption and ethyl carbamate. In: IARC Monographs on the Evaluation of Carcinogenic Risks in Humans; vol 96. Lyon, France: $n$ IARC Working Group on the Evaluation of Carcinogenic Risks to Humans; 2010.

4. Pöschl G, Stickel F, Wang XD, Seitz HK . Alcohol and cancer.
Alcohol. 2004;39(3):155-165. doi:10.1093/alcalc/agh057

5. Negri E, La Vecchia C, Franceschi S, et al. Attributable risk for oral cancer in Northern Italy. Cancer Epidemiol Biomarkers Prev. 1993;2:189-193. PMID:831887.

6. de Fiebre CM, Collins AC. A comparison of the development of tolerance to ethanol and crosstolerance to nicotine after chronic ethanol treatment in long- and short-sleep mice. J Pharmacol Exp Ther. 1993;266(3):1398-1406 PMID:8371145.

7. Doyon WM, Thomas AM, Ostroumov A, et al. Potential Substrates for Nicotine and Alcohol Interactions: a Focus on the Mesocorticolimbic Dopamine System. Biochem Pharmacol. 2013;86(8):1181-1193. doi:10.1016/j.bcp.2013.07.007

8. Census and Statistics Department, Hong Kong Special Administrative Region. Thematic Household Survey Report No. 59: Pattern of smoking, Personal computer and Internet penetration, Use of language. Hong Kong: Census and Statistics Department, Hong Kong Special Administrative Region; 2016. https://www.statistics. gov.hk/pub/B11302592016XXXXB0100.pdf. Accessed December 23, 2020.

9. Department of Health, University of Hong Kong. Behavioural risk factor survey (April 2016). Hong Kong: Surveillance and Epidemiology Branch Centre for Health Protection Department of Health; 2017. https://www. chp.gov.hk/files/pdf/brfa_report_april_2016_eng.pdf. Accessed December 23, 2020.

10. Anand A, Roy N. Prevalence and determinants of couse of alcohol and tobacco among men in working age group (18-59 years) in India. Epidemiology, Biostatistics and Public Health. 2016;13(1):e116421-e116429. doi:10.2427/11642

11. Katulanda $P$, Ranasinghe $C$, Rathnapala A, et al. Prevalence, patterns and correlates of alcohol consumption and its' association with tobacco smoking among Sri Lankan adults: A cross-sectional study. BMC Public Health. 2014;14(1):612. doi:10.1186/1471-2458-14-612

12. Banta JE, Addison A, Job JS, et al. Patterns of alcohol and tobacco use in Cambodia. Asia Pac J Public Health. 2013;25(5 Suppl):33S-44S. doi:10.1177/1010539512464649

13. Fiore MC, Bailey WC, Bennett G, et al. A clinical practice guideline for treating tobacco use and dependence: 2008 Update. A U.S. Public Health Service Report. Am J Prev Med. 2008;35(2):158-176. doi:10.1016/j.amepre.2008.04.009

14. Lindson-Hawley N, Thompson TP, Begh R. Motivational interviewing for smoking cessation. Cochrane Database Syst Rev. 2015;(3):CD006936. doi:10.1002/14651858. CD006936.pub3

15. Lam TH, Abdullah AS, Chan SS, et al. Adherence to nicotine replacement therapy versus quitting smoking among Chinese smokers: a preliminary investigation. Psychopharmacology. 2005;177(4):400-408. doi:10.1007/s00213-004-1971-y 
16. Chan SSC, Lam TH. An evaluative study of the integrated smoking cessation services of Tung Wah Group of Hospitals. Hong Kong: Tung Wah Group of Hospitals; 2011.

17. Babor TF, Higgins-Biddle JC, Saunders JB. AUDIT: The alcohol use disorders identification test: Guidelines for use in primary care. Geneva, Switzerland: World Health Organization, Department of Mental Health and Substance Dependence; 2001. https://apps.who.int/iris/bitstream/ handle/10665/67205/WHO_MSD_MSB_01.6a-eng. pdf? sequence $=1 \&$ isAllowed=y. Accessed December 23, 2020.

18. Falk DE, Yi H, Hiller Sturmhöfel S. An epidemiologic analysis of co-occurring alcohol and tobacco use disorders: Findings from the National Epidemiologic Survey on Alcohol and Related Conditions. Alcohol Res Health. 2006;29(3):162-171. PMID:17373404.

19. Anthony JC, Echeagaray-Wagner F. Epidemiologic analysis of alcohol and tobacco use. Alcohol Res Health. 2000;24(4):201-208. PMID:15986714.

20. Aekplakorn W, Hogan MC, Tiptaradol S, et al. Tobacco and hazardous or harmful alcohol use in Thailand: Joint prevalence and associations with socioeconomic factors. Addict Behav. 2008;33(4):503-514. doi:10.1016/j.addbeh.2007.10.010

21. World Health Organization. Global Information System on Alcohol and Health. https://www.who.int/data/gho/ data/themes/global-information-system-on-alcohol-andhealth. Published 2016. Accessed December 23, 2020.

22. World Health Organization. Global status report on noncommunicable diseases 2010. Geneva, Switzerland: World Health Organization; 2011. https://www.who.int/data/ gho/data/themes/global-information-system-on-alcoholand-health. Accessed December 23, 2020.

23. Kirst M, Mecredy G, Chaiton M. The prevalence of tobacco use co-morbidities in Canada. Can J Public Health. 2013;104(3):e210-e215. doi:10.17269/cjph.104.3770

24. Kahler CW, Spillane NS, Metrik J. Alcohol use and initial smoking lapses among heavy drinkers in smoking cessation treatment. Nicotine Tob Res. 2010;12(7):781778. doi:10.1093/ntr/ntq083

25. Dawson DA. Drinking as a risk factor for sustained smoking. Drug Alcohol Depend. 2000;59(3):235-249. doi:10.1016/s0376-8716(99)00130-1

26. Moeller SJ, Fink DS, Gbedemah M, Hasin DS, Galea S, Zovlensky MJ, Goodwin RD. Trends in illicit drug use among smokers and non-smokers in the United States, 2002-2014. J Clin Psychiatry. 2018;79(3):17m11718. doi:10.4088/JCP.17m11718

27. Lau TFJ, Kim KH, Tsui HY. Prevalence, Health Outcomes, and Patterns of Psychotropic Substance Use in a Chinese Population in Hong Kong: A PopulationBased Study. Subst Use Misuse. 2005;40(2):187-209. doi:10.1081/ja-200048454

28. Tsai LT, Lo FE, Yang CC, et al. Influence of socioeconomic factors, gender and indigenous status on smoking in Taiwan. Int J Environ Res Public Health. 2016;25;13(11):1044. doi:10.3390/ijerph13111044

29. Carlson P, Almquist AY. Are area-level effects just a proxy for school-level effects? Socioeconomic differences in alcohol consumption patterns among Swedish adolescents. Drug Alcohol Depend. 2016;166:243-248. doi:10.1016/j.drugalcdep.2016.05.031

30. Intarut N, Pukdeesamai P. Socioeconomic Inequality in Concurrent Tobacco and Alcohol Consumption. Asian Pac J Cancer Prev. 2017;18(7):1913-1917. doi:10.22034/APJCP.2017.18.7.1913

31. M c K e S A, Weinberger A H. Annu Rev Clin Psychol.2013;9(1):649-674. doi:10.1146/annurev-clinpsy-050212-185549

\section{ACKNOWLEDGEMENTS}

We are much indebted to Derek Yee Tak Cheung of the University of Hong Kong for his statistical input.

\section{CONFLICTS OF INTEREST}

The authors have completed and submitted the ICMJE Form for Disclosure of Potential Conflicts of Interest and none was reported.

\section{FUNDING}

There was no source of funding for this research.

PROVENANCE AND PEER REVIEW

Not commissioned; externally peer reviewed. 